\section{Australian Journal of \\ Crop Science}

AJCS 14(04):660-666 (2020)

doi: $10.21475 /$ ajcs.20.14.04.p2304

\title{
Fruit canopy position and harvest date influence on colour and quality of Imperial mandarin (Citrus reticulata Blanco)
}

\author{
Prakash Adhikari ${ }^{1}$, Zora Singh ${ }^{1,2^{*}}$, Vijay Yadav Tokala ${ }^{1}$, Poe Nandar Kyaw ${ }^{1}$ and Bronwyn Walsh ${ }^{3}$ \\ ${ }^{1}$ School of Molecular and Life Sciences, Faculty of Science and Engineering, Curtin University, GPO Box U1987, Perth \\ 6845, Western Australia \\ ${ }^{2}$ Centre for Crop and Food Innovation, Western Australian State Agricultural Biotechnology Centre, College of \\ Science, Health, Engineering and Education, Murdoch University, Perth, Western Australia 6150, Australia \\ ${ }^{3}$ WA Citrus, PO Box 7205, Karawara, 6152 Western Australia
}

\author{
*Corresponding author: zora.horti@hotmail.com
}

Abstract

Rind colour and taste are important factors influencing consumer acceptance of mandarin (Citrus reticulata Blanco) fruit. In this experiment, the influence of fruit canopy position and harvest date on the fruit rind colour and other quality parameters of Imperial mandarins was investigated. The mandarin fruit were harvested from four different positions in the tree canopy i.e., upper-inner, upper-outer, lower-inner and lower-outer and at three different harvest dates $\mathrm{H}_{1}$ (five days before commercial harvest date); $\mathrm{H}_{2}$ (commercial harvest date) and $\mathrm{H}_{3}$ (five days after commercial harvest date). The experiment was conducted using a two factors (fruit position and harvest time) factorial randomised block design with four replicates and fifteen fruit per replicate. Rind colour and the quality of Imperial mandarins were significantly affected by the fruit position in the tree canopy, with the fruit harvested from the upper canopy having better rind colour and higher levels of organic acids and sugars compared to other positions. The late harvested $\left(\mathrm{H}_{3}\right)$ mandarins exhibited the best fruit colour. In conclusion, the Imperial mandarin fruit had better fruit colour as well as quality when harvested from the upper canopy and by delaying the fruit harvest date by five days from the original commercial harvest date.

Keywords: citric acid; citrus colour index; late harvest; rind colour; upper canopy

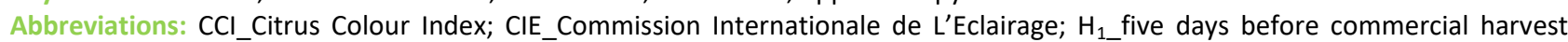
date; $\mathrm{H}_{2}$ commercial harvest; $\mathrm{H}_{3}$ five days after commercial harvest date; SSC_Soluble Solid Content; TA_Titratable Acidity

\section{Introduction}

Mandarin (Citrus reticulata Blanco.) fruit are popular throughout the world for their attractive appearance, sweet taste and easy peel characteristics (Moon et al., 2011). With the rise in demand for mandarins, global production has also increased by $30 \%$ from 22 million tonnes in 2010 to 29 million tonnes in 2015 (Neves et al., 2018). Fruit colour and taste play a major role in higher consumer acceptance of mandarins (Jayaprakasha and Patil, 2007). Several environmental, nutritional and tree factors are directly or indirectly responsible for the development of ideal fruit quality in the mandarin fruit (Khalid et al., 2012). The position of fruit in the tree canopy is one of the important factors affecting fruit quality (Khan et al., 2009). The fruit position in the tree determines the amount of sun exposure, which in turn affects the fruit quality by manipulating the different physiological and nutritional processes (Khalid et al., 2012). Kinnow mandarin fruit harvested from the upper canopy developed better colour and exhibited higher vitamin C content as well as soluble solid content: titratable acidity (SSC: TA) ratio values when compared to the fruit harvested from the lower canopy (Verma, 2015). Similarly, differences in the quality attributes of the fruit when harvested from different positions of the tree have also been reported in sweet oranges (Citrus sinensis L. Osbeck.) (Uchida et al., 1985), starfruit (Averrhoa carambola L.) (Zabedah et al., 2009) as well as in apple (Malus domestica Borkh.) (Drogoudi and Pantelidis, 2011).

Colour development and fruit quality of mandarins also depend on the harvesting date. The fruit colour indices in the early harvested mandarin fruit was inferior when compared to the fruit harvested at the recommended harvest date (Verma, 2015; Goldenberg et al., 2018). During the fruit maturation process, the SSC:TA significantly and then a gradual decrease in mandarin fruit (lqbal et al., 2012). Early harvested citrus fruit such as grapefruit (Citrus paradisi Macf.) and mandarin (Khalid et al., 2012) had higher levels of vitamin $\mathrm{C}$ when compared to late-harvested fruit.

The effect of fruit position in the tree canopy and harvest date on different fruit quality parameters has been previously studied in Kinnow mandarin and Nules Clementine mandarin (Khan et al., 2009; Khalid et al., 2012; Magwaza et al., 2013). However, there is no research 
reported on the effects of the fruit position in the tree canopy and the harvest date on the colour development and fruit quality in Imperial mandarin and it warrants investigation, as a popular variety grown in Australia. It was hypothesised that the fruit position in the tree canopy and the harvest date will influence the colour parameters and fruit quality in the Imperial mandarin. Therefore, the effect of various positions of fruit in the tree canopy and different harvesting dates on the rind colour and other quality parameters in Imperial mandarin fruit were investigated.

\section{Results}

\section{Fruit colour parameters $\left(L^{*}, a^{*}, b^{*}\right)$ and colour index (CCI)}

All the fruit colour parameters were significantly affected by the harvest dates and different positions of fruit in the tree canopy (Table 1). When averaged over different harvest dates, mean $L^{*}$ value was significantly $(P \leq 0.05)$ higher in the fruit harvested from the upper-inner canopy (44.04) compared to fruit harvested from the outer canopy positions (Table 1). When averaged over fruit positions in the tree canopy, mean $L^{*}$ values were not significantly different between different harvest dates. The interaction between the different positions of fruit in the tree canopy and harvest dates was not significant for the $L^{*}$ values.

The mean $a^{*}$ values of the fruit harvested from the upperinner canopy (24.14) and upper-outer canopy (23.28) were significantly $(P \leq 0.05)$ higher when compared to fruit from the lower tree canopy (Table 1 ). The harvest periods $\mathrm{H}_{2}$ and $\mathrm{H}_{3}$ resulted in significantly higher mean $\mathrm{a}^{*}$ values when compared to the fruit of early harvest $\left(\mathrm{H}_{1}\right)$. The interaction effect between the harvest dates and the different positions of fruit in the tree canopy was found to be significant for $a^{*}$ values. The fruit harvested early $\left(\mathrm{H}_{1}\right)$ from lower-outer (14.48) and lower-inner (14.40) position in the tree canopy showed significantly lower values. Comparatively lateharvested $\left(\mathrm{H}_{3}\right)$ fruit from upper-inner (24.72) and upperouter (24.23) exhibited significantly higher a* values when compared to all other harvest dates and the different positions of fruit on the tree canopy (Table 1).

When averaged over different harvest dates, the mean $b^{*}$ value was found to be higher in the fruit harvested from upper-inner (48.77) and upper-outer (47.81) positions of the tree canopy compared to all other positions. The mean $b^{*}$ values were found to be significantly $(P \leq 0.05)$ highest in the fruit harvested at harvest date $\mathrm{H}_{2}(49.02)$ as compared to harvest date $\mathrm{H}_{1}$ and $\mathrm{H}_{3}$. The interaction between different fruit positions in the canopy and different harvesting dates was not significant for $b *$ values. (Table 1 ).

The fruit harvested from upper-inner and upper-outer positions of tree canopy exhibited significantly $(P \leq 0.05)$ higher mean $\mathrm{CCl}$ values (11.23 and 11.31, respectively), compared to the fruit harvested from the lower-inner and lower-outer positions of the tree canopy, when averaged over different harvest dates. The late harvested $\left(\mathrm{H}_{3}\right)$ fruit exhibited significantly higher (10.87) mean $\mathrm{CCl}$ values when compared to other harvest dates. There was a significant interaction effect between harvest dates and the fruit position in the tree canopy. The fruit harvested late $\left(\mathrm{H}_{3}\right)$ from the upper-outer canopy (11.85) exhibited the highest $\mathrm{CCl}$ values compared to all other harvest dates, irrespective of fruit position in the tree canopy (Table 1).

\section{SSC: TA ratio}

When averaged over different harvest dates, the fruit harvested from an upper-inner position of the tree showed higher (11.50) SSC: TA ratio compared to other fruit positions (Table 2). When averaged over fruit position in the tree canopy, the mean SSC: TA ratio of early harvested fruit $\left(\mathrm{H}_{1}\right)$ was significantly $(P \leq 0.05)$ higher $(11.61)$ compared to the fruit harvested at $\mathrm{H}_{2}$ (10.63) and at $\mathrm{H}_{3}$ (10.46). The interaction between fruit position in the tree canopy and harvesting dates for SSC: TA ratio was found to be significant.

\section{Individual organic acids}

The reverse-phase high-performance liquid chromatography system (RP-HPLC) detected considerable amounts of citric acid and very low malic and succinic acid in the fruit juice samples studied. The levels of individual organic acids were significantly affected by the fruit position in the tree canopy. In general, the juice extracted from fruit harvested from the outer tree canopy exhibited higher levels of organic acids than the juice from the fruit in the inner canopy.

When averaged over different harvest dates, the mean citric acid content was significantly $(P \leq 0.05)$ higher in the pooled juice sample of the fruit harvested from the outer canopy (lower-outer canopy $\left(2.92 \mathrm{~g} \mathrm{~L}^{-1}\right.$ ) and upper-outer canopy $\left(2.74 \mathrm{~g} \mathrm{~L}^{-1}\right)$ compared to the fruit harvested from inner positions in the tree canopy (Table 3 ). The fruit harvested late $\left(\mathrm{H}_{3}\right)$ exhibited significantly $(P \leq 0.05)$ lower $\left(2.32 \mathrm{~g} \mathrm{~L}^{-1}\right)$ mean citric acid levels in their juice samples when compared to the juice samples from the fruit harvested at $\mathrm{H}_{1}\left(2.90 \mathrm{~g} \mathrm{~L}^{-}\right.$ ${ }^{1}$ ) and $\mathrm{H}_{2}\left(2.78 \mathrm{~g} \mathrm{~L}^{-1}\right)$.

When averaged over different harvest dates, mean levels of malic acid were lowest in the juice extracted from the fruit harvested from the lower-inner canopy compared to other canopy positions (Table 3). The interaction effect between the fruit position in the tree canopy and harvest dates was not significant for the levels of malic acid.

\section{Individual sugars}

The individual sugars such as fructose, glucose and sucrose were detected by the RP-HPLC system. In general, the individual sugars were higher in juice samples from the fruit harvested from the upper-outer and upper-inner canopy of the tree (Table 4). When averaged over different harvest dates, the mean fructose level was found to be significantly $(P \leq 0.05)$ higher $\left(65.01 \mathrm{~g} \mathrm{~L}^{-1}\right)$ in the juice samples of the fruit from the upper-outer canopy position compared to the fruit harvested from other positions in the tree canopy (Table 4). The mean glucose levels $\left(63.61 \mathrm{~g} \mathrm{~L}^{-1}\right)$ were found to be significantly $(P \leq 0.05)$ higher in the juice of fruit harvested from the upper-outer canopy position compared to the fruit harvested from other positions in the tree canopy (Table 4). There was no significant interaction effect between the harvest dates and the fruit harvested from different positions in the tree canopy for fructose and glucose.

The juice samples from the fruit harvested early $\left(\mathrm{H}_{1}\right)$ exhibited significantly $(P \leq 0.05)$ higher $\left(157.68 \mathrm{~g} \mathrm{~L}^{-1}\right)$ levels of sucrose compared to other harvest dates $\mathrm{H}_{2}$ and $\mathrm{H}_{3}$ (Table 4), when averaged over different positions in the tree canopy,. When averaged over different harvest dates, the 
Table 1. Effect of fruit position in the tree canopy and harvest dates on fruit colour parameters of Imperial mandarin fruit.

\begin{tabular}{|c|c|c|c|c|}
\hline \multicolumn{5}{|c|}{ Fruit Colour } \\
\hline \multicolumn{5}{|c|}{ Harvest Dates } \\
\hline Fruit Position & $\mathrm{H}_{1}$ & $\mathrm{H}_{2}$ & $\mathrm{H}_{3}$ & Means $\left(F_{p}\right)$ \\
\hline \multicolumn{5}{|c|}{$L^{*}$} \\
\hline Lower-inner & $42.80 \pm 1.56$ & $44.07 \pm 0.21$ & $43.91 \pm 1.31$ & $43.60 \mathrm{BC}$ \\
\hline Lower-outer & $40.50 \pm 1.50$ & $41.03 \pm 1.64$ & $41.42 \pm 1.13$ & $40.98 \mathrm{~A}$ \\
\hline Upper-inner & $43.21 \pm 0.88$ & $44.72 \pm 0.26$ & $44.18 \pm 0.59$ & $44.04 \mathrm{C}$ \\
\hline Upper-outer & $43.18 \pm 0.78$ & $42.61 \pm 0.84$ & $43.02 \pm 0.42$ & $42.93 \mathrm{~B}$ \\
\hline Mean $\left(H_{D}\right)$ & 42.42 & 43.11 & 43.13 & \\
\hline \multicolumn{5}{|c|}{$a^{*}$} \\
\hline Lower-inner & $14.40 \pm 2.61 \mathrm{a}$ & $21.18 \pm 0.47 \mathrm{~cd}$ & $20.68 \pm 2.56 \mathrm{~cd}$ & $18.75 \mathrm{~B}$ \\
\hline Lower-outer & $14.48 \pm 2.26 a$ & $16.77 \pm 2.64 \mathrm{ab}$ & $18.95 \pm 1.84 \mathrm{bc}$ & $16.73 \mathrm{~A}$ \\
\hline Upper-inner & $23.13 \pm 0.74 \mathrm{de}$ & $24.55 \pm 0.47 \mathrm{e}$ & $24.72 \pm 0.15 \mathrm{e}$ & $24.14 \mathrm{C}$ \\
\hline Upper-outer & $23.22 \pm 0.50 \mathrm{de}$ & $22.38 \pm 0.80 \mathrm{de}$ & $24.23 \pm 1.07 \mathrm{e}$ & $23.28 \mathrm{C}$ \\
\hline Mean $\left(H_{D}\right)$ & $18.81 \mathrm{~A}$ & $21.22 \mathrm{~B}$ & $22.15 \mathrm{~B}$ & \\
\hline \multicolumn{5}{|c|}{$\mathrm{b}^{*}$} \\
\hline Lower-inner & $43.35 \pm 2.28$ & $50.19 \pm 0.35$ & $46.74 \pm 1.87$ & $46.76 \mathrm{~B}$ \\
\hline Lower-outer & $41.14 \pm 1.70$ & $45.06 \pm 1.37$ & $44.44 \pm 1.82$ & $43.55 \mathrm{~A}$ \\
\hline Upper-inner & $46.19 \pm 0.85$ & $51.45 \pm 0.11$ & $48.68 \pm 0.23$ & $48.77 \mathrm{C}$ \\
\hline Upper-outer & $46.55 \pm 0.67$ & $49.36 \pm 1.02$ & $47.51 \pm 0.85$ & $47.81 \mathrm{BC}$ \\
\hline Mean $\left(\mathrm{H}_{\mathrm{D}}\right)$ & $44.31 \mathrm{~A}$ & $49.02 \mathrm{C}$ & $46.84 \mathrm{~B}$ & \\
\hline \multicolumn{5}{|c|}{$\mathrm{CCl}$} \\
\hline Lower-inner & $7.37 \pm 0.95 a$ & $9.59 \pm 0.32 \mathrm{~cd}$ & $9.98 \pm 0.78 \mathrm{~cd}$ & $8.98 \mathrm{~A}$ \\
\hline Lower-outer & $8.30 \pm 1.13 a b$ & $8.77 \pm 0.91 b c$ & $10.14 \pm 0.51 b c$ & $9.07 \mathrm{~A}$ \\
\hline Upper-inner & $11.49 \pm 0.31 \mathrm{fg}$ & $10.70 \pm 0.20 \mathrm{fg}$ & $11.51 \pm 0.21$ ef & $11.23 \mathrm{~B}$ \\
\hline Upper-outer & $11.56 \pm 0.23 \mathrm{fg}$ & $10.51 \pm 0.03 \mathrm{fg}$ & $11.85 \pm 0.28$ def & $11.31 \mathrm{~B}$ \\
\hline Mean $\left(H_{D}\right)$ & $9.67 \mathrm{~A}$ & $9.90 \mathrm{~A}$ & $10.87 \mathrm{~B}$ & \\
\hline
\end{tabular}

$\mathrm{H}_{\mathrm{D}}=$ harvest date, $\mathrm{F}_{\mathrm{P}}=$ fruit position, $\mathrm{n}=4$ replicates (10 fruit per replication), mean $\pm \mathrm{SD}$. Duncan's multiple range test at $(P \leq 0.05)$ was used to test the mean separation for significant analysis of variance within the column and rows. Means followed by the same letter are not significantly different within the column or rows. Means within columns or rows without letters are non-significant.

Table 2. Effect of fruit position in the tree canopy and harvest date on SSC: TA ratio in the juice of Imperial mandarin fruit.

\begin{tabular}{lcccc}
\hline \multicolumn{5}{c}{ Harvest Dates } \\
\hline Fruit Position & $\mathrm{H}_{1}$ & $\mathrm{SSC}: \mathrm{TA}$ & $\mathrm{H}_{3}$ & Means $\left(\mathrm{F}_{\mathrm{P}}\right)$ \\
\hline Lower-inner & $12.08 \pm 1.39 \mathrm{e}$ & $9.95 \pm 0.54 \mathrm{ab}$ & $10.86 \pm 0.74 \mathrm{bcd}$ & $10.84 \mathrm{BC}$ \\
Lower-outer & $12.42 \pm 0.32 \mathrm{e}$ & $10.56 \pm 1.04 \mathrm{abcd}$ & $9.53 \pm 0.43 \mathrm{a}$ & $10.96 \mathrm{AB}$ \\
Upper-inner & $11.48 \pm 0.30 \mathrm{cde}$ & $11.62 \pm 0.42 \mathrm{de}$ & $11.42 \pm 0.50 \mathrm{cde}$ & $11.50 \mathrm{C}$ \\
Upper-outer & $10.47 \pm 0.29 \mathrm{abcd}$ & $10.38 \pm 0.63 \mathrm{abc}$ & $10.02 \pm 0.13 \mathrm{ab}$ & $10.29 \mathrm{~A}$ \\
Mean $\left(\mathrm{H}_{\mathrm{D}}\right)$ & $11.61 \mathrm{~B}$ & $10.63 \mathrm{~A}$ & $10.46 \mathrm{~A}$ &
\end{tabular}

$\mathrm{H}_{\mathrm{D}}=$ harvest date, $\mathrm{F}_{\mathrm{P}}=$ fruit position, $\mathrm{n}=4$ replicates (15 fruit per replication), mean $\pm \mathrm{SD}$. Duncan's multiple range test at $(P \leq 0.05)$ was used to test the mean separation for significant analysis of variance within the column and rows. Means followed by the same letter are not significantly different within the column or rows.

Table 3. Effect of fruit position in the tree canopy and harvest date on citric acid and malic acid levels in the juice of Imperial mandarin fruit

\begin{tabular}{|c|c|c|c|c|}
\hline \multicolumn{5}{|c|}{ Individual organic acids $\left(\mathrm{g} \mathrm{L}^{-1}\right)$} \\
\hline \multicolumn{5}{|c|}{ Harvest Dates } \\
\hline Fruit Position & $\mathrm{H}_{1}$ & $\mathrm{H}_{2}$ & $\mathrm{H}_{3}$ & Means $\left(F_{P}\right)$ \\
\hline \multicolumn{5}{|c|}{ Citric acid } \\
\hline Lower-inner & $2.80 \pm 0.16$ & $2.50 \pm 0.14$ & $2.34 \pm 0.29$ & $2.55 \mathrm{~A}$ \\
\hline Lower-outer & $3.07 \pm 0.22$ & $3.06 \pm 0.32$ & $2.63 \pm 0.32$ & $2.92 \mathrm{~B}$ \\
\hline Upper-inner & $2.62 \pm 0.16$ & $2.71 \pm 0.22$ & $2.04 \pm 0.20$ & $2.46 \mathrm{~A}$ \\
\hline Upper-outer & $3.11 \pm 0.22$ & $2.85 \pm 0.15$ & $2.27 \pm 0.24$ & $2.74 \mathrm{~B}$ \\
\hline Mean $\left(H_{D}\right)$ & $2.90 \mathrm{~B}$ & $2.78 \mathrm{~B}$ & $2.32 \mathrm{~A}$ & \\
\hline \multicolumn{5}{|l|}{ Malic acid } \\
\hline Lower-inner & $0.67 \pm 0.19$ & $0.69 \pm 0.32$ & $0.72 \pm 0.22$ & $0.69 \mathrm{~A}$ \\
\hline Lower-outer & $0.67 \pm 0.30$ & $0.96 \pm 0.02$ & $0.87 \pm 0.06$ & $0.83 \mathrm{AB}$ \\
\hline Upper-inner & $0.73 \pm 0.20$ & $0.92 \pm 0.05$ & $0.86 \pm 0.03$ & $0.84 \mathrm{AB}$ \\
\hline Upper-outer & $0.91 \pm 0.06$ & $1.03 \pm 0.03$ & $0.95 \pm 0.04$ & $0.96 \mathrm{~B}$ \\
\hline Mean $\left(H_{D}\right)$ & 0.74 & 0.90 & 0.85 & \\
\hline
\end{tabular}

$\mathrm{H}_{\mathrm{D}}=$ harvest date, $\mathrm{F}_{\mathrm{P}}=$ fruit position, $\mathrm{n}=4$ replicates (15 fruit per replication), mean $\pm \mathrm{SD}$. Duncan's multiple range test at $(P \leq 0.05)$ was used to test the mean separation for significant analysis of variance within the column and rows. Means followed by the same letter are not significantly different within the column or rows. Means within columns or rows without letters are non-significant. 
Table 4. Effect of fruit position in the tree canopy and harvest date on individual sugar levels in the juice of Imperial mandarin fruit.

\begin{tabular}{|c|c|c|c|c|}
\hline \multicolumn{5}{|c|}{ Individual sugars $\left(\mathrm{g} \mathrm{L}^{-1}\right)$} \\
\hline \multicolumn{5}{|c|}{ Harvest Dates } \\
\hline Fruit Position & $\mathrm{H}_{1}$ & $\mathrm{H}_{2}$ & $\mathrm{H}_{3}$ & Means $\left(F_{p}\right)$ \\
\hline \multicolumn{5}{|l|}{ Fructose } \\
\hline Lower-inner & $49.61 \pm 1.83$ & $51.82 \pm 1.90$ & $55.06 \pm 0.83$ & $49.55 \mathrm{~A}$ \\
\hline Lower-outer & $54.64 \pm 1.16$ & $51.89 \pm 1.20$ & $55.06 \pm 0.99$ & $53.86 \mathrm{~B}$ \\
\hline Upper-inner & $62.55 \pm 1.57$ & $62.39 \pm 0.54$ & $59.78 \pm 2.73$ & $61.57 C$ \\
\hline Upper-outer & $67.11 \pm 2.05$ & $65.81 \pm 1.37$ & $62.11 \pm 0.68$ & $65.01 \mathrm{D}$ \\
\hline Mean $\left(H_{D}\right)$ & 58.48 & 57.98 & 56.04 & \\
\hline \multicolumn{5}{|l|}{ Glucose } \\
\hline Lower-inner & $45.32 \pm 1.74$ & $47.97 \pm 1.15$ & $44.15 \pm 1.26$ & $44.15 \mathrm{~A}$ \\
\hline Lower-outer & $50.73 \pm 2.00$ & $50.42 \pm 1.98$ & $53.84 \pm 1.76$ & $51.66 \mathrm{~B}$ \\
\hline Upper-inner & $60.44 \pm 2.10$ & $59.52 \pm 0.88$ & $58.74 \pm 3.04$ & $59.57 \mathrm{C}$ \\
\hline Upper-outer & $64.69 \pm 2.94$ & $65.82 \pm 1.65$ & $60.33 \pm 1.34$ & $63.61 \mathrm{D}$ \\
\hline Mean $\left(H_{D}\right)$ & 55.30 & 55.94 & 54.26 & \\
\hline \multicolumn{5}{|l|}{ Sucrose } \\
\hline Lower-inner & $153.46 \pm 4.46$ & $147.07 \pm 7.83$ & $141.98 \pm 4.85$ & 147.51 \\
\hline Lower-outer & $157.46 \pm 3.10$ & $133.95 \pm 4.14$ & $142.88 \pm 6.11$ & 144.76 \\
\hline Upper-inner & $153.77 \pm 3.90$ & $152.11 \pm 4.72$ & $145.67 \pm 3.15$ & 150.52 \\
\hline Upper-outer & $166.00 \pm 4.73$ & $142.36 \pm 6.83$ & $133.93 \pm 1.63$ & 147.43 \\
\hline Mean $\left(H_{D}\right)$ & $157.68 \mathrm{~B}$ & $143.87 \mathrm{~A}$ & $141.12 \mathrm{~A}$ & \\
\hline
\end{tabular}

$H_{D}=$ harvest date, $F_{p}=$ fruit position, $n=4$ replicates (15 fruit per replication), mean \pm SD. Duncan's multiple range test at $(P \leq 0.05)$ was used to test the mean separation for significant analysis of variance within the column and rows. Means followed by the same letter are not significantly different within the column or rows. Means within columns or rows without letters are non-significant.

Table 5. Effect of fruit position in the tree canopy and harvest date on vitamin C and total antioxidant capacity in the juice of Imperial mandarin fruit

\begin{tabular}{|c|c|c|c|c|}
\hline \multicolumn{5}{|c|}{ Harvest Dates } \\
\hline Fruit Position & $\mathrm{H}_{1}$ & $\mathrm{H}_{2}$ & $\mathrm{H}_{3}$ & Means $\left(F_{p}\right)$ \\
\hline \multicolumn{5}{|c|}{ Vitamin $C\left(\mathrm{mg} \mathrm{L}^{-1}\right)$} \\
\hline Lower-inner & $54.28 \pm 1.90$ & $44.19 \pm 1.38$ & $43.79 \pm 0.82$ & $47.42 \mathrm{C}$ \\
\hline Lower-outer & $47.03 \pm 3.47$ & $42.40 \pm 1.91$ & $41.74 \pm 3.75$ & $43.72 \mathrm{~B}$ \\
\hline Upper-inner & $49.48 \pm 1.80$ & $41.00 \pm 1.57$ & $41.96 \pm 1.49$ & $44.14 \mathrm{~B}$ \\
\hline Upper-outer & $44.84 \pm 1.76$ & $38.64 \pm 2.23$ & $37.46 \pm 3.60$ & $40.31 \mathrm{~A}$ \\
\hline Mean $\left(H_{D}\right)$ & $48.91 \mathrm{~B}$ & $41.55 \mathrm{~A}$ & $41.24 \mathrm{~A}$ & \\
\hline \multicolumn{5}{|c|}{ Total antioxidant capacity $\left(\mu \mathrm{M}\right.$ Trolox $\left.\mathrm{L}^{-1}\right)$} \\
\hline Lower-inner & $92.20 \pm 2.57$ & $78.32 \pm 1.43$ & $66.93 \pm 3.77$ & $79.15 \mathrm{~B}$ \\
\hline Lower-outer & $91.21 \pm 2.92$ & $71.77 \pm 4.25$ & $69.24 \pm 5.31$ & $77.41 \mathrm{~B}$ \\
\hline Upper-inner & $89.73 \pm 3.28$ & $76.43 \pm 2.95$ & $70.23 \pm 4.85$ & $78.80 \mathrm{~B}$ \\
\hline Upper-outer & $85.28 \pm 2.92$ & $65.78 \pm 3.14$ & $63.21 \pm 5.17$ & $71.42 \mathrm{~A}$ \\
\hline Mean $\left(H_{D}\right)$ & $89.61 \mathrm{C}$ & 73.07 B & $67.40 \mathrm{~A}$ & \\
\hline
\end{tabular}

$H_{D}=$ harvest date, $F_{p}=$ fruit position, $n=4$ replicates (15 fruit per replication), mean \pm SD. Duncan's multiple range test at $(P \leq 0.05)$ was used to test the mean separation for significant analysis of variance within the column and rows. Means followed by the same letter are not significantly different within the column or rows. Means within columns or rows without letters are non-significant.

sucrose levels did not differ significantly $(P \leq 0.05)$ among the fruit harvested from different canopy positions. The interaction between harvest dates and the fruit harvested from different positions in the tree canopy for sucrose was not significant.

\section{Vitamin C}

When averaged over different harvest dates, the mean levels of the vitamin $C$ were significantly $(P \leq 0.05)$ highest (47.42 $\mathrm{mg} \mathrm{L}^{-1}$ ) in the juice samples extracted from the fruit harvested from the lower-inner canopy compared to the fruit from all other positions in the tree canopy (Table 5). When averaged over different positions in the tree canopy, early harvested fruit $\left(\mathrm{H}_{1}\right)$ exhibited significantly higher mean vitamin $\mathrm{C}$ levels (48.91 $\mathrm{mg} \mathrm{L}^{-1}$ ) compared to $\mathrm{H}_{2}$ and $\mathrm{H}_{3}$ harvest dates. The interaction between different fruit positions in the tree canopy and harvest dates on the vitamin C levels was not significant.

\section{Total antioxidant capacity}

When averaged over different harvest dates, the mean levels of total antioxidant capacity were found to be significantly $(P \leq 0.05)$ lower $\left(71.42 \mu \mathrm{M}\right.$ Trolox $\left.L^{-1}\right)$ in the juice of fruit harvested from the upper-outer canopy compared to the fruit harvested from all other positions in the tree canopy (Table 5). When averaged over different positions in the tree canopy, mean total antioxidant capacity levels were significantly $(P \leq 0.05)$ higher $\left(89.61 \mu \mathrm{M}\right.$ Trolox $\mathrm{L}^{-}$ $\left.{ }^{1}\right)$ in the juice of fruit harvested early $\left(\mathrm{H}_{1}\right)$ as compared to later harvest dates. The interaction between different fruit positions and harvesting times did not show any significant effect on the levels of the total antioxidant capacity. 
The colour is one of the important features which determines consumer acceptance of fruit and is therefore a major concern for marketing the fruit in domestic as well as international markets. The majority of consumers are likely to choose fruit with the optimum and uniform colour, characteristic of the particular fruit variety, and then later assess other fruit qualities (Wei et al, 2003). The fruit harvested from the upper canopy exhibited better values of different colour attributes and $\mathrm{CCl}$ than the fruit from the lower canopy (Table 1). The fruit in the upper canopy receives comparatively higher light intensity, which promotes the fruit colour development by the breakdown of chlorophyll pigment and carotenoid accumulation in the rind of citrus fruit (Rehman et al., 2018). Similar observations have also been reported in Nules Clementine and Mihowase Satsuma mandarin fruit (Verreynne et al., 2004). The fruit harvested late $\left(\mathrm{H}_{3}\right)$ showed higher $\mathrm{CCl}$ values compared to earlier dates (Table 1). These differences are due to the higher chlorophyll degradation and carotenoid accumulation with the extension in the harvest date allowing more time for fruit ripening (Goldenberg et al., 2018).

The exposure to light enhances the formation of sugars and breakdown of acids in the fruit (Khan et al., 2009). This can be seen in the significantly higher levels of glucose and fructose recorded in the juice samples from the fruit in the upper tree canopy. A similar rise in sugar levels was also reported in grapefruit (Syvertsen and Albrigo, 1980) and Nules Clementine and Mihowase Satsuma mandarins (Verreynne et al., 2004). The SSC: TA ratio was significantly higher in early harvested $\left(\mathrm{H}_{1}\right)$ fruit compared to $\mathrm{H}_{2}$ and $\mathrm{H}_{3}$. The similar decreasing trend of SSC: TA ratio with a delayed harvest date has also been reported in grapefruit (Syvertsen and Albrigo, 1980) and Kinnow mandarin fruit (Khalid et al., 2012).

The organic acid levels in the fruit juice influence the taste and it also acts as key determinants of the fruit maturity. The levels of citric and malic acids in the juice from the fruit collected from the outer canopy positions were higher compared to the fruit from inner positions within the tree canopy. Possibly, it may be ascribed to the breakdown of the acids in the fruit from the outer canopy of the tree with much exposure to light (Khan et al., 2009). The levels of citric acid exhibited a decreasing trend with delayed harvest dates. The decreasing trend in the levels of acids is due to breaking down of organic acids into sugars to utilise as respiratory substrates during fruit maturation process (Tucker, 2012). Previously, Khalid et al. (2012) also reported a similar trend in Kinnow mandarin fruit.

The levels of vitamin C and total antioxidant capacity were found to be significantly less in the fruit harvested from the upper-outer canopy of the tree compared to all other positions within the tree canopy. The levels of vitamin $C$ and total antioxidant capacity exhibited a declining trend with delay in the harvest times. Fruit maturation and ripening involves several oxidative processes and depletes vitamin C content and total antioxidant capacity during the process (Masia, 1998). The fruit exposed to higher sunlight intensity showed enhanced fruit maturation and ripening (Khan et al., 2009) and this could possibly be related to reduced levels of vitamin $\mathrm{C}$ content and total antioxidant capacity.

\section{Plant materials}

The mandarin (Citrus reticulata Blanco. cv. Imperial) fruit were hand-harvested from twelve-year-old mandarin trees previously grafted on Trifoliate orange (Poncirus trifoliata L. Raf.) rootstock grown in a commercial orchard at Harvey, Western Australia ( $33^{\circ} 04^{\prime} 48^{\prime \prime} \mathrm{S}, 115^{\circ} 53^{\prime} 40^{\prime \prime} \mathrm{E}$ ). The trees were planted in a North-South orientation with $2.5 \mathrm{~m}$ (within rows) $\times 6 \mathrm{~m}$ (between rows) spacing. The fruit were harvested from four different positions in the tree canopy i.e. upper-outer, upper-inner, lower-outer and lower-inner and at three different harvest dates $\left[\mathrm{H}_{1}\right.$ (five days before commercial harvest date) on $30^{\text {th }}$ May 2018; $\mathrm{H}_{2}$ (commercial harvest date) on $6^{\text {th }}$ June 2018 and $\mathrm{H}_{3}$ (five days after commercial harvest date) on $11^{\text {th }}$ June 2018]. The fruit harvested were immediately transferred to Curtin Horticulture Research Laboratory, Perth using an airconditioned vehicle within two hours. The experiment was laid out in a randomised block design with two factors (fruit position and harvest time). All the treatments were replicated four times with fifteen fruit in each replication. Ten randomly selected fruit per replicate were used to determine colour coordinates (CIE $\left.L^{*}, a^{*}, b^{*}\right)$ and to calculate the citrus colour index $(\mathrm{CCl})$. The pooled juice sample, extracted from fifteen fruit per replicate were used to determine SSC: TA, vitamin C, total antioxidant capacity as well as individual sugars and organic acids.

\section{Determination of fruit colour parameters}

The fruit colour coordinates (CIE $L^{*}, a^{*}$ and $\left.b^{*}\right)$ were recorded using Colorflex EZ $\left(45^{\circ} / 0^{\circ}\right.$ design) spectrocolorimeter (Hunter Lab, Hunter Associates Laboratory Inc., Reston, VA, USA) from ten randomly selected fruit per replication at two opposite sides at the equatorial region on each fruit. The values were expressed as Commission Internationale de L'Eclairage (CIE) L* (lightness/darkness), a* (redness/ greenness) and $b^{*}$ (yellowness/ blueness).

The citrus colour index $(\mathrm{CCl})$ was then calculated by using the formula (Jiménez-Cuesta et al, 1982; Rehman et al., 2018). $\quad \mathrm{CCl}=\frac{1000 \times \mathrm{a}^{*}}{\mathrm{~L}^{*} \times \mathrm{b}^{*}}$

\section{SSC: TA ratio}

A digital refractometer (Atago-Palette PR 101, Atago CO. Ltd, Itabashi-Ku, and Tokyo, Japan) was used to determine the SSC of fresh fruit juice samples and expressed as a 'percentage'. TA was determined based on a titration method using $5 \mathrm{~mL}$ of diluted juice $(3 \mathrm{x})$ and titrating against $0.1 \mathrm{~N}$ sodium hydroxide $(\mathrm{NaOH})$ solution, after adding 2-3 drops of phenolphthalein indicator, till pale pink colour endpoint (Sadler and Murphy, 2010). The volume of $\mathrm{NaOH}$ utilised to achieve the end-point was noted and used to calculate TA and expressed as per cent citric acid. The SSC: TA ratio was calculated by dividing the obtained SSC by TA.

\section{Determination of individual sugars and organic acids}

The concentrations of individual sugars and organic acids in the juice samples were determined using an RP-HPLC 
(Waters, Milford, MA, USA) following the method described previously by Rehman et al. (2018). The RP-HPLC was installed with a Dual $\lambda$ UV absorbance detector (Water 2487, Milford Corporation, USA) at $214 \mathrm{~nm}$ for organic acids determination and Refractive Index (RI) detector (Water 2414, Milford Corporation, USA) to determine individual sugars in the samples. Bio-Rad Aminex ${ }^{\circledast}$ HPX-87C Fast Carbohydrate column $(100 \times 7.8 \mathrm{~mm})$ (Bio-Rad Laboratories Inc., USA) was used to separate individual sugars and BioRad Aminex ${ }^{\circledR}$ HPX-87H column $(300 \times 7.8 \mathrm{~mm})$ (Bio-Rad Laboratories Inc., USA) to separate individual organic acids. The chromatographic peaks of different organic acids and sugars were identified, and the retention times were compared with peaks of standard chemicals. The amount of individual sugars and organic acids were quantified using Breeze ${ }^{\circledR}$ software (Waters, Milford, Massachusetts, USA) and the values were expressed as $\mathrm{g} \mathrm{L}^{-1}$ fresh juice.

\section{Determination of vitamin C and total antioxidant capacity}

The vitamin C (ascorbic acid) content and total antioxidant capacity in the fresh juice samples were estimated by using a UV/VIS spectrophotometer (Jenway spectrophotometer Model 6405, Dunmow, Essex, UK) and calculated by following the earlier method described by Sun et al. (2019). The values of vitamin C content were calculated based on the standard curve drawn using different concentrations of 98\% L-ascorbic acid against optical density (OD) values of the spectrophotometer. The values were expressed as $\mathrm{m} \mathrm{L} \mathrm{L}^{-1}$ of fresh juice.

The total antioxidant capacity was determined following the method described by Brand-Williams et al. (1995) with some modifications as explained previously by Sun et al. (2019). The values were calculated from the standard curve drawn using 6-hydroxy 2,5,7,8-tetramethylchromane-2-carboxylic acid (Trolox) and expressed as $\mu \mathrm{M}$ Trolox $\mathrm{L}^{-1}$ of fresh juice.

\section{Statistical analysis}

All the experimental data were analysed using GenStat $14^{\text {th }}$ edition (release 14.1; Lawes Agricultural Trust, Rothamsted experimental station, UK) by two-way (fruit position and harvest date) analysis of variance (ANOVA). Significant differences $(P \leq 0.05)$ and interaction among various treatments were calculated using Duncan's multiple comparison tests.

\section{Conclusions}

Imperial mandarin fruit harvested from the upper tree canopy exhibited good rind colour. Higher levels of individual organic acids and sugars, which are key determinants of the fruit taste, were also recorded in the fruit harvested from the upper canopy. The fruit harvested late had better fruit colour compared to other harvest dates. In conclusion, the position of fruit in the tree canopy and harvest date affect the fruit quality in Imperial mandarin. Harvesting fruit five days after commercial harvest date from the upper canopy of the tree would exhibit good rind colour and better quality likely to have higher consumer acceptance.

\section{Acknowledgements}

We are grateful to Mr Richard Eckersley for providing access to his orchard at Harvey, Western Australia and the fruit required for this research. We are thankful to Ms Helen Newman for assisting in fruit harvesting and to Ms Susan Petersen for technical support.

References

Brand-Williams W, Cuvelier ME, Berset CLWT (1995) Use of a free radical method to evaluate antioxidant activity. LWTFood Sci Technol. 28(1): 25-30.

Drogoudi PD, Pantelidis G (2011) Effects of position on canopy and harvest time on fruit physico-chemical and antioxidant properties in different apple cultivars. Sci Hortic. 129(4): 752-760.

Goldenberg L, Yaniv Y, Porat R, Carmi N (2018) Mandarin fruit quality: a review. J Sci Food Agric. 98(1): 18-26.

Iqbal M, Khan M, Zafar M, Munir M (2012) Effect of harvesting date on fruit size, fruit weight and total soluble solids of Feutrell's early and Kinnow cultivars of mandarin (Citrus reticulata) on the economic conditions of farming community of Faisalabad. Sarhad J Agric. 28(1): 19-21.

Jayaprakasha G, Patil BS (2007) In vitro evaluation of the antioxidant activities in fruit extracts from citron and blood orange. Food Chem. 101(1): 410-418.

Jiménez-Cuesta M, Cuquerella J, Martinez-Javaga JM (1982) Determination of a color index for citrus fruit degreening. In: Matsumoto $\mathrm{K}$ (ed) Proceedings of the international society of citriculture, Tokyo, Japan, 1982-1983.

Khalid S, Malik AU, Saleem BA, Khan AS, Khalid MS, Amin M (2012) Tree age and canopy position affect rind quality, fruit quality and rind nutrient content of 'Kinnow' mandarin (Citrus nobilis Lour $\times$ Citrus deliciosa Tenora). Sci Hortic. 135: 137-144.

Khan AS, Malik A, Pervez M, Saleem BA, Rajwana I, Shaheen T, Anwar R (2009) Foliar application of low-biuret urea and fruit canopy position in the tree influence the leaf nitrogen status and physico-chemical characteristics of Kinnow mandarin (Citrus reticulata Blanco). Pak J Bot. 41(1): 73-85.

Magwaza LS, Opara UL, Cronje PJ, Landahl S, Terry LA (2013) Canopy position affects rind biochemical profile of 'Nules Clementine' mandarin fruit during postharvest storage. Postharvest Biol Technol. 86: 300-308.

Masia A (1998) Superoxide dismutase and catalase activities in apple fruit during ripening and post-harvest and with special reference to ethylene. Physiol Plantarum. 104(4): 668-672.

Moon DG, Joa JH, Moon YE, Seong KC, Kim CH, Ahn YK (2011) Plant growth and fruit quality as affected by canopy locations in 'Shiranuhi' mandarin. Hortic Environ Biotech. 52(5): 443-447.

Neves CG, doAmaral DOJ, de Paula MFB, de Nascimento LS, Costantino G, Passos OS, do Amaral Santos M, Ollitrault P, da Silva Gesteira A, Luro F, Micheli F (2018) Characterization of tropical mandarin collection: Implications for breeding related to fruit quality. SciHortic. 239: 289-299.

Rehman M, Singh Z, Khurshid T (2018) Pre-harvest spray application of abscisic acid (S-ABA) regulates fruit colour development and quality in early maturing M7 Navel orange. Sci Hortic. 229: 1-9. 
Sadler GD, Murphy PA (2010) pH and titratable acidity. In: Neilsen S (ed) Food analysis, Springer, Boston, MA. pp. 219-238.

Sun Y, Singh Z, Tokala VY, Heather B (2019) Harvest maturity stage and cold storage period influence lemon fruit quality. Sci Hortic. 249: 322-328.

Syvertsen J, Albrigo L (1980) Some effects of grapefruit tree canopy position on microclimate, water relations, fruit yield, and juice quality. J Amer Soc Hortic Sci. 105(3): 454459.

Tucker GA (2012) Introduction. In: Seymour G, Taylor J, Tucker $G$ (eds) Biochemistry of fruit ripening. Springer, Dordrecht, Netherlands. pp. 1-51.

Uchida M, Yoshinaga K, Kawose K (1985) Studies on the effects of the microclimate of fruit, with regard to fruit quality of late maturing citrus cultivars. I. The relationship between fruit quality, fruit position in the canopy and fruit microclimate in the orange cultivar (Fukuhara). Bull Fruit Trees Res Stn Jpn. 7: 39-55.

Verma M (2015) Effect of nutrition, harvesting date and fruit canopy position on yield and quality of Kinnow mandarin (Citrus nobilis $\times$ Citrus deliciosa). Indian J Agri Sci. 85(11): 1455-1460.

Verreynne JS, Rabe E, Theron KI (2004) Effect of bearing position on fruit quality of mandarin types. S Afr J Plant Soil. 21(1): 1-7.

Wei S, Singgih S, Woods EJ, Adar D (2003) How important is appearance? Consumer preferences for mandarins in Indonesia. Int J Consum Stud. 27(5): 406-411.

Zabedah M, Yusoff A, Ridzwan H, Fauzi R, Hassan S (2009). Effects of fruit canopy position on chemical composition and fruit colour development of starfruit cultivated under the netted structure. J Trop Agric Food Sci. 37(2): 135-142. 